\title{
Stage II Thyroid Gland Papillary Carcinoma AJCC v8
}

National Cancer Institute

\section{Source}

National Cancer Institute. Stage II Thyroid Gland Papillary Carcinoma A/CC v8. NCI

Thesaurus. Code C140980.

Stage II includes: Under 55 years: Any T, Any N, M1; 55 years and older: (T1, N1, M0); (T2, N1, M0); (T3a/T 3b, Any N, M0). T1: Tumor measuring $2 \mathrm{~cm}$ or less in greatest dimension limited to the thyroid. T2: Tumor measuring more than $2 \mathrm{~cm}$ but $4 \mathrm{~cm}$ or less in greatest dimension limited to the thyroid. T3a: Tumor measuring more than $4 \mathrm{~cm}$ in greatest dimension limited to the thyroid. T3b: Gross extrathyroidal extension invading only strap muscles (sternohyoid, sternothyroid, thyrohyoid, or omohyoid muscles) from a tumor of any size. N1: Metastasis to regional nodes. M0: No distant metastasis. M1: Distant metastasis. (from AJCC 8th Ed.) 